\title{
Potential Spending on Veterans' Medical Care
}

\author{
Heidi Golding \\ Congressional Budget Office
}

The U.S. Department of Veterans Affairs provides medical care to a large share of veterans. This paper describes some of the distinctive features of the system-including the services provided, funding mechanism, and cost to veterans. It then examines the growth in the cost of providing services over the past decades and of expanding access to medical care by non-VA providers and facilities. The paper presents two projections of VA spending growth over the next decade, both of which could raise concerns about affordability in a period of constrained federal budgets.

Keywords: Veterans, Public Health, Health Care Spending

\section{INTRODUCTION}

The U.S. Department of Veterans Affairs (VA) provides medical care to many veterans. In 2017, there were approximately 21 million living veterans with service in the United States military. Just over 9 million veterans were enrolled in the VA system in 2017, of whom about 6 million sought treatment that year. Federal spending for the VA medical program (including medical research but not construction of medical facilities or payments from patients or third parties) totaled $\$ 69$ billion in 2017, or about $\$ 7,600$ per enrollee. (All spending amounts in this paper are reported in 2018 dollars; all years are federal fiscal years). By comparison, federal spending on the program was $\$ 27$ billion in 2000, or less than one-half of current levels. Growth in the program was due to many factors, among them the aging of the veteran population, growth in the number of veterans with VA-determined service-connected disabilities, and changes in VA's policies and programs. Changes in the law in the mid-1990s and the past decade have expanded access substantially. Among its other provisions, the VA MISSION Act, enacted in 2018, expands access to medical care as provided by private community providers but paid for by VA. VA anticipates that it will require $\$ 9$ billion in 2020 and $\$ 11$ billion in 2021 to implement the MISSION Act (VA, 2019a).

We provide two projections of higher spending by VA. The first projection is based on an assumption that VA's current policies will remain in place (and includes the costs anticipated to implement the MISSION Act). For this projection, we used data from several sources, including detailed data on enrollment and current spending for VA enrollees, near-term costs of the MISSION Act as calculated by VA, and the growth in health care spending per capita as projected by the Centers for Medicare and Medicaid Services. This projection suggests that VA spending for medical care may grow considerably in the next decade (after adjusting to remove the effects of economywide inflation).

There is a large degree of uncertainty in this projection. The growth in spending in national health care may vary depending on such factors as advances in health care or legislative changes. In addition, 
little is known about veterans' likelihood to enroll or change their use of VA with changes in access to care or other factors. Varying the methodology or assumptions of the model result in many other potential paths for spending.

To illustrate another path VA spending might take, we present a second projection based largely on past growth rates in spending per enrollee from the last decade. This simpler projection is not tied to specific legislative or administrative changes. Rather, it continues the rate of growth of VA health costs that has occurred. In broad terms, the second projection's results are similar to those found in the first projection, i.e., that VA health costs will increase considerably in real terms in upcoming years.

\section{DISTINCTIVE FEATURES OF THE VA'S MEDICAL CARE SYSTEM}

The VA medical care system has several features unusual in the U.S. medical system, including its organization, the services or mix of services offered, cost to veterans, and funding mechanism. VA has traditionally provided the vast majority of its care through the facilities it operates. Its network includes about 170 medical centers as well as more than 1,000 outpatient clinics, rehabilitation facilities, and nursing homes. VA states that it seeks to coordinate care from different providers within the system through various means and to provide a continuum of services to veterans (VA, 2019b). As such, VA is one of the largest integrated health care delivery systems in the U.S. (Enthoven, 2009).

VA provides a broad set of medical care services. Many are similar to those provided elsewhere, although some are not generally offered through typical insurance coverage. Medical care provided by VA includes hospital care, outpatient primary and specialty care, counseling services, rehabilitation and prosthetic care, diagnostic tests, prescriptions and over-the-counter medications, and assistive devices such as prescription glasses, hearing aids and supplies, and mobility assistance. VA also offers long-term care (at a cost of roughly $\$ 9$ billion in 2017), including nursing home care, adult home and respite care. Special VA programs target reducing homelessness among veterans or support caregivers by providing stipends and health care (at a cost of more than $\$ 2$ billion for those two programs in 2017). VA also has some additional programs in place to improve access to veterans. For instance, some veterans receive reimbursement for travel to VA facilities, or use telehealth or mobile clinics.

VA specializes in some areas of medical care, and the mix of VA services received by veterans differs from the mix in the private sector. For example, some enrollees rely heavily on VA's mental health services, prosthetics or rehabilitation care.

Most of VA's medical services or products are delivered at relatively low or no cost to the veterans. There are no deductibles or enrollment fees. Copayments for visits are $\$ 15$ for primary care visits and $\$ 50$ for specialty visits for some veterans, but those copayments do not apply to all veterans or visits. For example, there are no out-of-pocket expenses for veterans treated for service-connected disabilities (medical conditions or injuries that VA determined occurred or worsened during military service). Pharmacy copayments vary from zero to $\$ 11$ per 30-day fill. In 2017, the average out-of-pocket cost for the year was less than $\$ 100$ per enrolled veteran (or less than 2 percent of VA's medical care spending). In contrast, enrollees in Part B of Medicare (which covers physicians' services) typically paid premiums of more than $\$ 100$ per month plus 20 percent of the Medicare-approved medical fees.

Finally, VA medical care is, for the most part, funded through annual appropriations acts, so that VA's medical spending is determined by lawmakers. In any given year, the Congress decides the department's budget - which can be higher or lower than that requested by VA in their annual budget submission. That budget determines the amount of care veterans can receive.

\section{ACCESS TO VA HEALTH CARE}

\section{Eligibility}

Most veterans are eligible for VA's medical care but they must enroll to receive treatment. When they apply, veterans are assigned to one of eight priority groups based on their service-connected disabilities, income, combat status, and other factors. VA determines how many priority groups it can serve within the 
funding approved by the Congress. Veterans in the lowest-priority (highest numeric value) groups would be the first to be denied service. Currently, new enrollment in priority group 8, which includes higherincome veterans without compensable service-connected disabilities, is restricted, and as a result about 5 million veterans who would be assigned to that group are not eligible to enroll. (Some additional veterans, including those who do not meet minimum military service or nature of discharge requirements, may not receive VA medical care.)

\section{Legislative Actions}

Historically, veterans had only restricted access to VA medical care-largely, for episodic care. But, in the past decades, access to VA's medical care has grown substantially. The Veterans' Health Care Eligibility Reform Act of 1996 permitted VA to offer medical care to all veterans to the extent that resources and facilities were available. VA consequently expanded medical care to those veterans without VA-determined service-connected disabilities and to those with higher incomes. The number of patients treated rose from about 3 million in 1996 to 4.5 million in 2003. In addition, VA realigned its medical services away from providing primarily inpatient care towards outpatient care, expanding the number of clinics in the late 1990s and early 2000s from about 175 in 1996 to roughly 700 by 2004.

Since 2014, there has also been a movement towards the provision of community care-medical care provided outside of VA facilities but paid for by VA - to increase veterans' access to VA-provided medical care. Although there were long-standing VA programs that authorized community care, usually in limited circumstances, to some groups of enrolled veterans, such as those who have service-connected disabilities, Congress enacted the Veterans Access, Choice, and Accountability Act of 2014 (or VA Choice Act) creating a temporary program which broadened the eligibility of enrollees to obtain community care. About $\$ 5$ billion of the $\$ 12$ billion VA spent on community care in 2017 was paid for by funds appropriated for that program. (As of July 2019, VA no longer offers community care to veterans under the VA Choice Program.)

In 2018, the VA MISSION Act was signed into law, which further expanded veterans' access to community care. The MISSION Act requires VA to establish the Veterans Community Care Program (VCCP), replacing long-established and the temporary community care programs. It specified that VA provide community care in several situations, such as when VA facilities do not offer the medical care needed or when a veteran cannot get care in a manner that complies with VA's standards for timely access to treatment. In 2019, VA promulgated regulations for VCCP, in part specifying new VA access standards (Office of the Federal Register, 2019a). To be eligible for community care, VA specified access standards which include: the driving time for the veteran is no more than an average of 30 minutes for VA primary care, mental health, and non-institutional extended care services, or an average of 60 minutes for VA specialty care, or, the wait times for an appointment cannot be over 20 or 28 days depending on the type of appointment. VA also allows veterans to receive community care under other situations including if a veteran and the referring VA clinician determine it is in the best medical interest of the veteran to do so. In effect, the new law and subsequent regulations further broaden the criteria for offering community care and extend eligibility. VA anticipates that it will require $\$ 9$ billion for the implementation of the MISSION Act in 2020 and \$11 billion in 2021 (VA, 2019a). (Several other provisions in the MISSION Act also affect veterans' health care or other VA programs, but their costs are less significant.)

\section{LONG-TERM TRENDS IN VA'S MEDICAL CARE SPENDING AND ENROLLMENT}

Between 1970 and 2017, VA's medical care spending grew significantly faster than the rate of economywide inflation (see Figure 1). VA spent about $\$ 69$ billion on medical care in 2017 , more than seven times as much as the $\$ 9$ billion VA spent in 1970. (All costs in this paper are expressed in 2018 dollars.) Spending increased to $\$ 27$ billion in 2000 and then accelerated. Spending for that care increased at an average annual rate of 6.4 percent between 2000 and 2010. Since then, the pace of growth has slowed to an average of 4.7 percent annually above inflation. A continued rise in costs is a potential challenge for future federal budgets, particularly since current spending reflects only a fraction of the 
potential costs the agency could incur if all eligible veterans enrolled and sought all of their care from VA.

The increase in VA's medical spending is particularly noteworthy because the number of veterans, which grew from about 28 million in 1970 to 30 million in 1980, has declined in the decades since then to about 21 million in 2017.

\section{FIGURE 1 \\ HISTORICAL SPENDING AND VETERAN POPULATION}

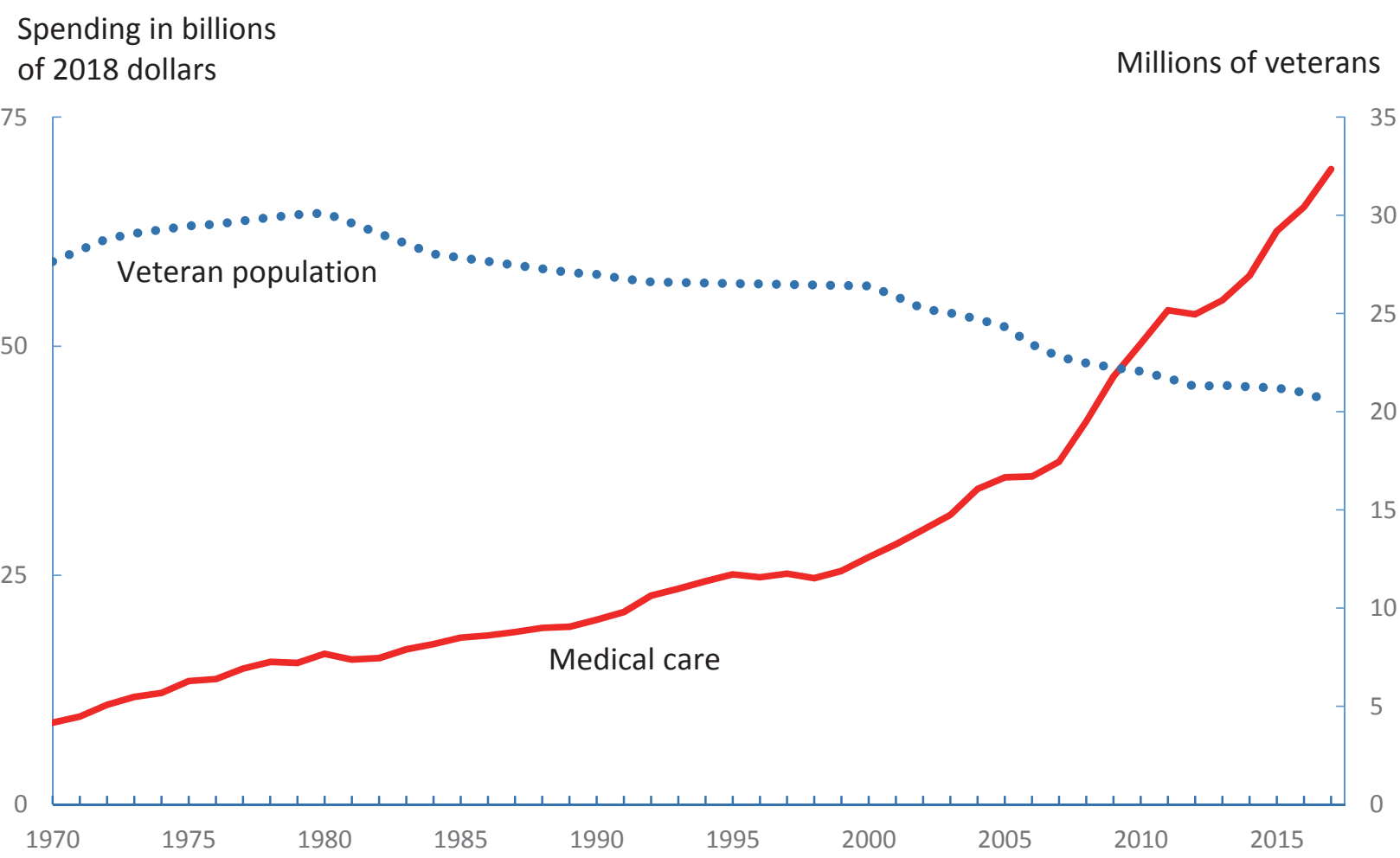

There are two primary reasons why costs have risen. First, the share of veterans who enrolled in the VA system has grown sharply since 2000, from 20 percent to 46 percent between 2000 and 2017, in part because VA broadened eligibility and expanded facilities. In 2000, enrollment stood at 5.1 million. It reached 7.0 million in 2003, an average annual rate of growth of 11 percent over that three-year period. However, VA lacked the funding to treat more patients at that point, so it restricted the ability of higherincome veterans to enroll in VA's system. Enrollment grew at a slower pace thereafter, rising to 9.1 million by 2017. Although most veterans are neither disabled nor lower-income (as determined by VA), roughly two-thirds of those who enroll in VA are assigned to priority groups that include serviceconnected disabled (priority groups 1 through 3 ) or lower-income veterans (priority group 5).

Second, since 2000, VA medical spending per enrollee has increased substantially, from $\$ 5,300$ in 2000 to $\$ 7,600$ in 2017. Between 2000 and 2010, average annual spending per enrollee grew by 1.5 percent more than the rate of inflation. However, the increase was uneven. Expenditures per enrollee fell briefly after 2000 (by about 15 percent through 2003), as healthier veterans enrolled and used more of the newly available outpatient services rather than more costly inpatient care. After 2003, spending per enrollee began to rise again, in part because the mix of enrollees shifted to higher-cost priority groups (such as service-connected disabled veterans). After 2010, average annual spending per enrollee grew at 3.1 percent per annum. 
Several additional factors are likely to have led to increased spending per enrollee since 2000. For one, the aging of the Vietnam-era population contributed to the increased costs, as the health of those enrollees deteriorated when they entered their 50s and 60s. Rising costs for health care in the general economy probably also affected VA's medical spending because the agency is subject to many of the same pressures as the private sector, such as higher prices for supplies and increased compensation for medical practitioners. Additionally, VA's per-enrollee costs may have increased because the amount of care enrollees sought from VA rather than other sources of care-a ratio known as the rate of reliancemay have increased as the private sector insurance market and other factors influencing reliance have changed (VA, 2019a). On average, enrollees rely on VA for about 35 percent of their medical care. (About 80 percent of enrollees have other medical care available to them.) Contrary to public perception, the average cost to care for combat veterans who served on or after September 11, 2001 (Gulf War II combat veterans) is relatively low-less than one half the average amount spent per enrollee - and it has not been a major driver in spending growth, yet.

\section{PROJECTED SPENDING, 2018-2028}

In this section, we project two possible paths for higher growth in VA medical care spending. We do not predict future appropriations by Congress but rather illustrate what VA's spending would be if the Congress appropriated funding under various assumptions.

\section{Methodology}

\section{Projection 1}

Our first projection of VA spending is based on the level of funding the Congress would need to appropriate to pay for medical care under VA's current policies and to implement the MISSION Act. Other than the MISSION Act, the projection incorporates no other major changes in current policies, such as VA's eligibility rules and cost-sharing. This projection anticipates that VA would continue to provide essentially the same package of services as it provides currently.

The projection allows the mix of enrollees, the use of medical services per enrollee, and medical inflation to vary. To project medical care spending (other than that required to implement the MISSION Act), we used VA's projections of the future number of enrollees in each priority group. Among other factors, the enrollment projections incorporate anticipated changes in the number and combat status of service members separating from military service and observed patterns in new enrollment. We used the most recent values for the veterans' rates of reliance and the relative costs of caring for enrollees in each priority group throughout the projection period. We estimated the future cost to the VA of providing that medical care per user, applying the anticipated growth in national health care spending per capita (as projected in the National Health Expenditures by the Centers for Medicare and Medicaid Services which we adjusted for differences in the veteran population) to the average cost of a user by priority group.

In addition, the projection includes the effects of the MISSION Act on medical spending. From 2019 to 2023, we incorporate the projected spending required to implement the act, as based on two sources: information reported in the Congressional Budget Office's (CBO's) cost estimate for the legislation, which estimated costs for the then-proposed law assuming a five-year implementation period that ends in 2023, and more recently reported information from VA, which detail newly defined programmatic elements and their costs for the initial years of the program, 2020 and 2021 (CBO, 2018a; VA, 2019a; VA, 2019c). After 2023, the projection incorporates the assumption that the spending required to implement the MISSION Act's community care provision grows at the same rate per enrollee as health care spending is anticipated to grow in the general economy. We project that the cost of other provisions would grow as a measure of wage and salary growth, as represented by the ECI, or by health care per capita spending, depending on the provision. This projection also incorporates the end of the VA Choice Program in 2019. (For more detail on the methodology, see CBO, 2018b.) 


\section{Projection 2}

To illustrate another path VA spending might take, we also constructed another (simpler) projection. Because our assumption that current policies will continue does not accord with past experience, we use historical growth as a guide to future spending. Specifically, the projection illustrates how costs would grow if actions by the Congress and the President, VA, and the courts required increased VA spending at the same rate as they have increased in recent years. For 2019 to 2023, we assume spending growth will mimic that in the first projection - that VA will require those increases to implement the MISSION Act as estimated and that no additional growth would occur as VA focusses its resources on implementing VCCP and the law's other provisions. After 2023, the projection increases spending per enrollee for medical care at rates similar to those experienced by VA in the past 10 years (3.9 percent annually).

\section{Discussion}

Both projections suggest that VA spending for medical care will grow in the next decade (adjusted for inflation), although at a slower rate than experienced in recent years (see Table 1). In the first projection which extends current policies, the spending for VA's medical care program increases to $\$ 107$ billion in 2028, an average annual growth rate from 2017 to 2028 of 4.0 percent above inflation. The second projection has VA medical care spending increasing to $\$ 110$ billion in 2028 with an average annual growth rate of 4.3 percent. These projections are broadly consistent with others' research, although those published studies were conducted prior to the MISSION Act (Eibner, 2015; Ghosh, 2017).

TABLE 1

\section{VA MEDICAL CARE SPENDING AND RECIPIENTS UNDER TWO PROJECTIONS}

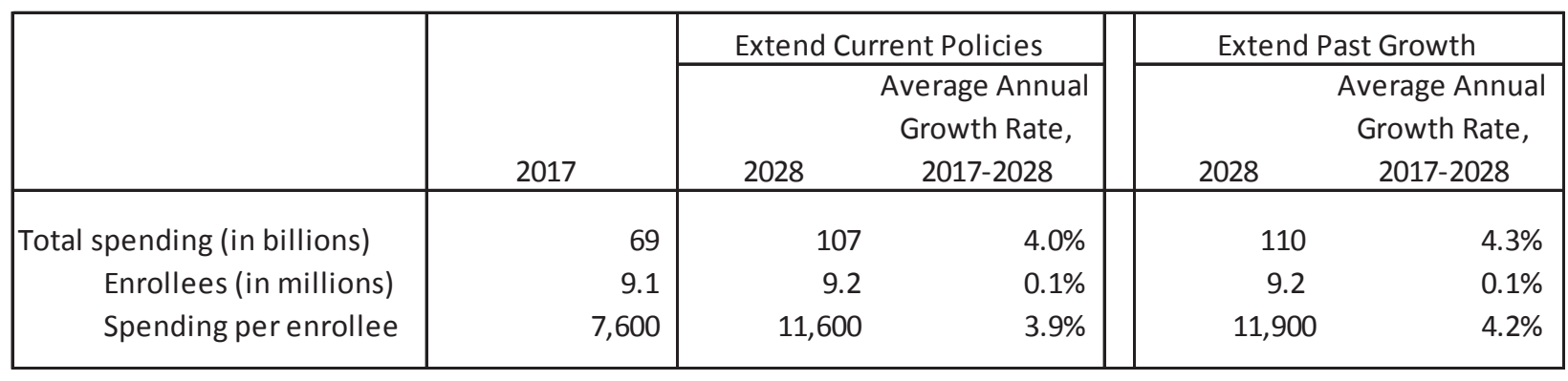

\section{Projection 1 (Extend Current Policies)}

Under this projection, enrollment in VA's medical care program would increase from 9.1 million in 2017 to 9.4 million by 2022 and then drop back down to 9.2 million by 2028, stemming in part from an anticipated decline in the number of combat veterans leaving the military. At the same time, however, a greater share of enrollees will be veterans with service-connected disabilities because we expect that the number of veterans receiving VA disability compensation will continue to increase and that the vast majority of disability compensation recipients will enroll in VA's medical care program. In 2018, about 50 percent of enrolled veterans (from priority groups 1,2, and 3) are estimated to have service-connected disabilities; that is expected to increase to about 60 percent in 2028. Because veterans with serviceconnected disabilities also generally cost more to care for than other veterans, their share of VA's medical spending (excluding the spending for the MISSION Act) would increase from about 60 percent to nearly 75 percent in 2028 . The changing mix of enrollees towards higher-cost priority groups adds roughly $\$ 10$ billion to spending in 2028 .

Besides the spending associated with the VA MISSION Act, spending growth for medical care under this scenario is largely driven by the assumption that medical expenditures per enrollee grow at about the same rate as they would in the general population. Aging of the veteran population will probably not contribute substantially to the growth in spending because most Vietnam veterans are now over 65 and thus are eligible for Medicare. (At that age, veterans' reliance on VA drops and the costs to VA per 
veteran decline until they begin using long-term medical services, such as nursing home care, in substantial numbers.) Gulf War II combat veterans will continue to enroll and likely use more VA medical care through 2028. Their health care costs to the VA are anticipated to grow from the current $\$ 6$ billion but are likely to remain relatively low through the projection period as they are typically younger and healthier than the average VA enrollee.

There is a substantial degree of uncertainty in this projection. First, the growth in spending in health care at the national level may vary depending on such factors as advances in health care technologies or legislative changes. Second, as the health care delivery and insurance markets evolve over the next 10 years, it seems likely that enrollment and reliance will change; however, the direction or magnitude of any future change is uncertain. Third, little is known about veterans' likelihood to enroll or change their use of VA with changes in access to care or other factors. VA's cost estimate for VCCP assumes that overall enrollment is not influenced by the new community care program. An increase in enrollment of 10 percent would increase the spending in 2028 by more than $\$ 10$ billion, assuming new enrollees use VA similarly to current ones. Fourth, changes to VA's policies and benefits may occur. Varying the methodology or assumptions of the model result in many other potential paths for spending.

\section{Projection 2 (Extend Past Growth)}

Our second projection lifts the assumption that current medical care policies continue for the projection period. We find that extending past growth in per enrollee spending results in spending for medical care growing to $\$ 110$ billion in 2028 , an annual average increase of 4.3 percent - only slightly faster than the first projection extending current policies. The rise in spending per enrollee would be the primary driver of the growth in medical spending.

\section{CONCLUSIONS}

VA's medical care program provides comprehensive care to millions of veterans. However, growth in the costs of providing that care may be a challenge to federal budgets. In this paper, we present two different projections of future VA health costs-illustrating what VA's spending would be if the Congress appropriated funding under some varying assumptions. Although spending increases in both projections, these projections are not meant to imply that spending will necessarily rise; there is large uncertainty about the level of spending and the Congress can limit spending growth. The first projection illustrates the sensitivity of spending due to anticipated higher-than-inflation increases in overall medical spending in the economy. Changes in the veteran population-either the number of veterans or the number of service-connected disabled veterans using the program - and policy or program changes also can substantially affect the costs of delivering VA medical care to veterans. The sensitivity of spending to these factors suggests that any changes to the VA system ought to be evaluated in a framework that considers the costs and cost-effectiveness of that change and the use and value of that benefit to veterans. 


\section{REFERENCES}

Congressional Budget Office. (2018a). Cost Estimate for H.R. 5674, VA Maintaining Internal Systems and Strengthening Integrated Outside Networks Act of 2018 (enacted as S. 2372). Retrieved from https://www.cbo.gov/publication/53871.

Congressional Budget Office. (2018b). Possible Higher Spending Paths for Veterans' Benefits. Retrieved from https://www.cbo.gov/publication/54881.

Eibner, C., et al. (2015). Current and Projected Characteristics and Unique Health Care Needs of the Patient Population Served by the Department of Veterans Affairs. Santa Monica, CA: RAND Corp. Retrieved from https://www.rand.org/pubs/research_reports/RR1165z1.html.

Enthoven, A.C. (2009). Integrated Delivery Systems: The Cure for Fragmentation. American Journal of Managed Care, 15(10), s284-s290.

Ghosh, P.P., Negrusa, S., \& Warner, J.T. (2018). Health Insurance, Health Conditions, and Veteran Health Care Utilization. Defense and Peace Economics, 29(1), 24-43.

U.S. Department of Veterans Affairs. (2019a). FY 2020 Budget Submission. Retrieved from https://www.va.gov/budget/products.asp.

U.S. Department of Veterans Affairs. (2019b). FY 2018 - 2024 Strategic Plan. Retrieved from https://www.va.gov/oei/docs/VA2018-2024strategicPlan.pdf.

U.S. Department of Veterans Affairs. (2019c). Economic Regulatory Impact Analysis for RIN 2900AQ46(F), Veterans Community Care Program. Retrieved from https://www.va.gov/ORPM/FY_2019_Published_VA_Regulations.asp.

U.S. Office of the Federal Register. (2019a). Federal Register for Friday, February 22, 2019, Proposed Rules, 38 CFR Part 17, 84(36). Retrieved from https://www.va.gov/ORPM/docs/20190222_AQ46_VeteransCommunityCareProgram.pdf

U.S. Office of the Federal Register. (2019b). Federal Register for Wednesday, June 5, 2019, Rules and Regulations, 38 CFR Part 17, 84(108). Retrieved from https://www.va.gov/ORPM/docs/20190605_AQ46_VeteransCommunityCareProgram.pdf. 